\title{
Examining the Performance of Islamic and Conventional Stock Indices: A Comparative Analysis
}

\author{
Mehmet Asutay $^{1}$ (D) Yumeng Wang ${ }^{1} \cdot$ Alija Avdukic $^{2}$
}

Accepted: 7 September 2021 / Published online: 24 September 2021

(c) The Author(s) 2021

\begin{abstract}
Islamic indices encompass different fundamental principles to those held by conventional ones, which directs attention onto comparative financial performance. This paper offers a comprehensive performance comparison between Islamic indices and conventional indices, based on four main markets: worldwide, the US, Europe and Asia-Pacific for the period of 2007 and 2017 through financial ratio comparison and also the CAPM-EGARCH model. The main finding shows that Islamic indices yield higher average returns and lower risks during the 2007-2009 and 2013-2017 periods for all four markets, compared with respective conventional markets. During 2009-2013 period, the comparison proves inconclusive, since Islamic indices demonstrate better performance in European and Asia-Pacific markets, while conventional indices operate at an enhanced level within other markets. Overall, Islamic indices outperformed conventional indices during the global financial crisis period (2007-2009) and the latter post-crisis phase (2013-2017), especially in the European and Asia-Pacific markets.
\end{abstract}

Keyword Islamic stock indices · Conventional indices · Financial ratios · CAPMEGARCH model $\cdot$ Systematic risk

Mehmet Asutay

mehmet.asutay@durham.ac.uk

Yumeng Wang

wangyumeng369@qq.com

Alija Avdukic

A.Avdukic@almcollege.ac.uk

1 Durham Centre for Islamic Economics and Finance, Durham University Business School, Durham, UK

2 Al-Maktoum College of Higher Education \& School of Business, University of Dundee, Dundee, Scotland, UK 


\section{Background}

The Islamic banking and finance sector has experienced substantial and unprecedented growth during the last two decades. While the assets held in the sector were mere US $\$ 10$ billion in 1985, as reported by IFSB (2021), the assets have reached US\$2.7 trillion in 2020. The size of the Islamic financial industry is predicted to gradually grow coupled with the increasing demand from non-Muslim majority countries. Based on the rapid growth of the Islamic finance industry, several indices have emerged to provide a filter system to screen stocks in the Islamic realm as well screening the conventional stocks through Shari'ah by applying several ethical and legal considerations to ensure these stocks are Shari'ah compliant in terms of business activity, accounting and financial screening (Obaidullah, 2005; Derigs \& Marzban, 2008; Bin Mahfooz \& Habib, 2014; Ashraf, 2016; Kafou \& Chakir, 2017; Tahir \& Ibrahim, 2020; Tanin et al., 2021).

Islamic stocks offer alternative investment choice to provide investment diversity, as Shari'ah-compliant investment has a lower leverage ratio among financial products and is asset-backed whereby the Islamic equity investments offer a better risk-adjusted performance compared to its conventional peer as observed during the global financial crisis (Akguc \& Al Rahahleh, 2020; Ashraf \& Mohammad, 2014). However, some research (Hayat \& Kraeussl, 2011) evidence no significant differences between both types of stocks and indicate Islamic stock's poor performance.

This paper aims to examine the comparative performance of Islamic and conventional stocks as captured by indices between July 2007 and June 2017 in four main markets-worldwide, the US, Europe and Asia-Pacific through standard ratios and the CAPM-EARCH model by measuring the return and volatility for both types of indices with the risk-adjusted return. To capture the dynamics of the markets, the analysis is also conducted by disaggregating the data into three periods, 2007-2009, 2013-2017 and 2009-2013, which helps to capture potential structural breaks. The determinants of the observed performance of both conventional and Islamic stock are also examined.

The contribution of this study lies in its original assessment of Islamic and conventional stocks under different conditions, as previous studies on Islamic finance mainly focused on the short-term analysis before and after the financial crisis. Considering that during the 2006-2016 period, the scale of the Islamic financial industry increased three-fold (GIFR, 2018), this study contributes to the existing body of knowledge by also capturing the dynamics in the expansion phase of the Islamic finance industry.

Since the beginning of the new century, the observed rapid growth of the Islamic financial industry has also led to increased accumulation of wealth in Muslim countries with alternative financing and investment methods. In responding to such performance and growth, an increasing number of conventional investors from non-Muslim countries are also involved in investing in Shari'ah compliant stock or the Islamic financial sphere. Furthermore, Islamic finance's increased legitimacy and viability have paved the way for diversified and high 
interest in Shari'ah compliant financing spheres such as Islamic capital and Islamic financial markets. Thus, while there has been increasing Islamic finance activity in terms of supply, diversity in demand from different sectors moving into the Islamic finance sphere to benefit from its alternative offerings have increased, such as non-Muslim majority countries issuing sovereign sukuk (Islamic bonds) as well as diverse interest from investors in Islamic stocks. Thus, the post-global financial crisis has witnessed further diversity in Islamic finance offerings as well as diversity in participants. This can be explained by the resilience and performance of the industry during and aftermath of the global financial crisis, which has ensured its proposition among investors and regulators. It is also important to state the successful performance, and its resilience has been despite the decline in oil prices and hence oil wealth, as Islamic finance's emergence has been attributed to oil wealth in the GCC region, which was considered to create dependency. However, the post-global finance period covered in this study is also where the oil prices declined, yet Islamic finance's expansions in volume, size, institutionalisation and new geographies have continued. This implies that markets, investors and individuals have convinced that Islamic finance and its offerings are viable propositions and will have sustained growth. Therefore, with the dramatic change of the Islamic financial industry during the last three decades, academic scholars also diversified their research direction. Specifically, academic scholars put much attention on evaluating the Islamic financial industry and comparing the Islamic financial market with the conventional financial market in different scenarios, including the comparative performance of Islamic and the conventional stocks as also covered by this study.

In comparison to the available literature, this paper, hence, conducts a more comprehensive comparison between Islamic and conventional indices with a longer sample period across different regions (worldwide, the US, Europe and Asia-Pacific), which should also be considered an important contribution in comparison to the available studies. In addition, considering the limits and facilitation of the market conditions, such as the bull and bear market periods, should also be regarded as a significant contribution. This implies that most of the studies in the field mainly conducted after the 2008 global financial crisis, which were confined to the initial recovery period after the crisis, but they could not extend into better market conditions. This study covers the post-global financial crisis recovery period until 2017.

Given the increased financial interest in Islamic finance in general and in the performance of Islamic indices in particular, the findings in this study are useful for investors who are concerned with financial performance as well as Islamic ethicality as a reflection of social responsibility.

The rest of the paper is structured as follows: Sect. 2 reviews the existing literature from theoretical perspectives, while Sect. 3 presents a brief review of empirical studies. Section 4 details the specific methodology used in this study. The empirical analysis is presented in Sect. 5, while Sect. 6 offers concluding remarks. 


\section{Islamic Screening Process}

Islamic finance works under Shari'ah law which imposes several normative and operational constraints; accordingly, four main tenets bind Islamic financial principles are: prohibition of transactions involving interest (riba); involving uncertainty (gharar) and gambling (maysir) as well as investment in forbidden industries which engage in unethical activities (DeLorenzo, 2000; Obaidullah, 2005; Asutay, 2015; el Alaoui et al., 2016; Ashraf, 2016; Alahouel \& Loukil, 2020; Cheong, 2021).

In responding to the rapid growth of the Islamic finance industry, notable global financial index service providers developed indices to meet the requirements of this niche market. The DJIM index, launched in 1999, is the first global Shari'ah-compliant index provider. Subsequently, the Financial Times Stock Exchange (FTSE), Morgan Stanley Capital International (MSCI), Standard and Poor's (S\&P) along with others have begun to provide index consisting of Shari'ah-compliant firms. While there are several Islamic indices on offer, the DJIM index has produced the most comprehensive time-series data for Shari'ah-compliant firms, which is used widely in academic circles (Hammoudeh et al., 2014; Shahzad et al., 2017; Shamsuddin, 2014).

While the screening rules of each index may vary, Shari'ah-compliant investment must pass both qualitative and quantitative screening. The first step excludes firms whose businesses do not comply with Shari'ah law, which is followed by screening through financial ratios related to the liquidity of assets (Ashraf, 2016; Bin Mahfooz \& Habib, 2014). For example, in the case of DJIM, to the first screening, all companies related to alcohol, tobacco, pork-related products, conventional financial services, entertainment, weapons and defence are removed. Secondly, accountingbased or financial ratio screening process necessitates that the following financial ratios must remain less than 33\% (Bin Mahfooz \& Habib, 2014; Derigs \& Marzban, 2008; Kafou \& Chakir, 2017): (1) debt screening: 'total debt' to 'trailing 24-month average market capitalization' ratio; (2) liquidity screening: 'cash and interest-bearing securities' to 'trailing 24-month average market capitalization'; (3) accounts receivable screening: 'accounts receivables' to 'trailing 24-month average market capitalization'. Lastly, impermissible or non-Shari'ah compliant income should not exceed 5\% of total non-interest income (Ashraf, 2016; Bin Mahfooz \& Habib, 2014; Derigs \& Marzban, 2008; Kafou \& Chakir, 2017).

Concerning S\&P Shari'ah indices, it utilises a similar screening rule to DJIM with some differences. Firstly, trading gold and silver as cash on a deferred basis and cloning are forbidden. Secondly, it accepts limited forms of the media industry, such as news channels, newspapers and sports channels. Concerning the financial ratio screen, it applies the same screening criteria as DJIM for the debt and the sum of cash and interest-bearing securities to the market value average ratio, but S\&P use the 36-month average value to determine the market value. Accordingly, the accounts related to the average market value ratio needs to be less than $49 \%$. Finally, it accepts less than $5 \%$ of non-permissible income in all profit. The FTSE Shari'ah Global Equity Index Series operates similar rules as S\&P. 


\section{Review of Empirical Studies}

The scholarly analysis focuses on evaluating Islamic equity indices from different standpoints. A particular trend in research involves the interest rate risk and the stock return co-movement. For example, Shamsuddin (2014) used weekly data from DJIM and FTSE and corresponding industry-sector indices taken from between 1996 and 2011. He found that the sector portfolios of Islamic stocks have a lower interest exposure risk compared to their main conventional counterparts. However, Umar et al. (2018), using the data for the 1996-2015 period, show that the Islamic stock market has considerable negative exposure to interest rate risk. They also find that the performance of Islamic equities do not differ from their mainstream counterpart regarding interest rate sensibility.

As Islamic finance is based on religious precepts, it may affect investors' behaviour or market performance. Therefore, Mazouz et al. (2016) found comovement in the Islamic stock correlated to religious events such as Ramadan, the month of fasting. They derived the data from the DJIM World Index (DJIMWI) between 1999 and 2012 from 18 countries. In their empirical process, Mazouz et al. (2016) associated the fluctuation of return in DJIMWI with the month of Ramadan evidencing that asset prices are affected by Islamic religious practice. Similarly, Klein et al. (2017) using event study methodology measured abnormal returns for sukuk issuance during Ramadan between 2000-2013, who demonstrated that sukuk were valued more than bond issuance by stock market.

Since Shari'ah compliant companies have specific financial ratio requirements, such as low leverage, Hayat and Hassan (2016) evidence that the Islamic companies might offer better governance compared to conventional indices. Through analysing data from both Islamic and conventional stock in S\&P 500 between 2001 and 2013, the results show that there was no significant governance difference between these stocks. The findings of Anwer et al. (2020) demonstrate that the drivers of better payout comes for Islamic compliant firms are related to lower governance level and lower market/book asset ratio for the period 2006-2018 of US firms.

Since the Islamic financial industry has limited investment option due to the Shari'ah constraints, Islamic stock offers the opportunity to hedge risks associated with conventional stock in the bear market or in other stressful conditions. For example, Narayan et al. (2017) compared the impact of financial news on both Islamic and conventional stocks with data collected from nine Islamic stock indices and nine conventional indices taken from Dow Jones Stock indices between 2005 and 2012. They found that positive news has a great effect on these two stocks while negative news has a relatively low effect on Islamic stocks and conventional stocks. Furthermore, Narayan et al. (2017), who examined 2066 stocks for the 1998-2012 period, confirm the sensibility of Islamic stocks to financial news containing a risk premium. Based on the nature of news being good, the profit ratio for risk-averse investors from Islamic and conventional stocks was $11.61 \%$ and $8.56 \%$, respectively. Concerning adverse news, the annual profit for Islamic stocks and conventional stocks yield $16.86 \%$ and $12.12 \%$, respectively. 
Similarly, Muteba Mwamba et al. (2017) compared the performance of Islamic and conventional stocks in the case of extreme financial events, such as the Black Swan and Asian currency crisis by using block maxima method and peak-overthreshold method with data sampled from DJIM, S\&P500, SPEU and SPAS500 indices between 1998 and 2015. Their results show Islamic markets were less risky compared to the conventional market during extreme events. Godil et al. (2020) also evaluated the behaviour of Islamic and conventional stocks under bullish market conditions for 1997-2019, whose findings also confirm that Islamic stocks behaviour differently from conventional.

The available literature compared between Islamic and conventional stocks by also focusing on the performance of risk and return in non-crisis and financial crisis periods. In such studies, profitability and risk is treated as the main determinants of the investment portfolio for global investors. However, the literature suggests mixed results. For example, by utilizing t-test and CAPM to compare the average return difference of various samples and evaluates the risk and return between two indices through the application of traditional ratios for 2002 and 2011 period, Ho et al. (2014) finds Islamic stock outperformed the conventional stock during the financial crisis, but the findings for comparisons in non-crisis periods remains inconclusive. Similarly, Albaity and Mudor (2012) found no significant difference between the performance of Islamic stock and conventional counterparts. In a recent study, AlYahyaee et al. (2020) located better performance of Islamic stocks across full sample period, who also confirms better performance of conventional stocks in the precrisis periods whereas Islamic stocks dominated in post-crisis periods.

In examining the financial crisis period, Jawadi et al. (2014) found conventional stock demonstrated a better performance before the financial crisis compared with Islamic stock, whereas Islamic stock outperformed conventional stock during the global financial crisis and yielded less impact from the financial crisis compared to its conventional counterpart. After the financial crisis, no significant difference between both stocks was demonstrated in applying data selected from the DJIM (Europe, USA and the World) for the 2000-2011 period by examining two sub-periods, namely calmness (2000-2007) and financial crisis (2007-2011) periods.

\section{Methodology and Data Selection}

\subsection{Data and Sampling}

The data for Islamic indices are selected from the DJIM index for July 2007 and June 2017. The monthly closing data for Islamic and the conventional indices were exported from Bloomberg data services. Compared with the other well-known Islamic indices, such as Morgan Stanley Capital International (MSCI) and Standard and Poor's (S\&P), DJIM offers the most complicated data supply and the longest time-series data, since it is the first Islamic Index instituted in 1999. To consider peculiarities of geographic areas, the comparison between Islamic and conventional index is also conducted at 'world', 'the US', 'European', and 'Asia-Pacific' markets. The conventional indices in the respective regions are benchmarks to compare to 
Shari'ah-compliant indices. Table 1 shows the data source for each market provided by Dow Jones Indices.

The performance comparison is conducted in two different sub-period: the financial crisis and a non-crisis period. The former incorporates July 2007 to June 2009. Shahzad et al. (2017) and Ho et al. (2014) also selected the same period as a financial crisis sub-period to compare it to the calm period between Islamic indices and the conventional indices. In this study, the calm period is divided into two parts: the early post-crisis period between July 2009 and June 2013, and the late post-crisis period detailing July 2013 to June 2017. Although, previous studies have used similar sub-periods, most have applied a limited data comparison; this paper extends the comparison period for the past financial crisis. It should also be noted that the US treasury-bill rate in each region is also considered a risk-free quotient.

\subsection{Empirical Method}

For the comparative performance of Islamic stocks and its conventional counterpart, it is necessary to measure the value for expected returns and related risks. A wide range of tools to measure risk under different considerations is available. This paper mainly focuses on three types of ratios: the Sharpe (SR), Roy (RR), and Treynor ratio (TR) being the most widely applied in previous studies.

$$
R_{i t}=\frac{\text { IndexValue }_{i t}-\text { IndexValue }_{i t-1}}{\text { IndexValue }_{i t-1}}
$$

where $R_{i t}$ is the return of stock index $i$ in time $t$; IndexValue ${ }_{i t}$ is the value of index $i$ in time $t$.

The SR (1966) (SR) measures the average excess return per unit of risk in the investment:

$$
\mathrm{SR}=\frac{\mathrm{R}_{\mathrm{i}, \mathrm{t}}-\mathrm{R}_{\mathrm{f}, \mathrm{t}}}{\sigma_{\mathrm{i}, \mathrm{t}}}
$$

where $\mathrm{R}_{\mathrm{i}, \mathrm{t}}$ as defined earlier, and $\mathrm{R}_{\mathrm{f}, \mathrm{t}}$ stands for risk-free return in time $t$, while $\sigma_{i, t}$ is the standard deviation (risk) for stock in state $i$ and in time $t$. SR (1966) can be used to compare the expected excess return of different portfolios with similar risk. Therefore, a higher ratio means that this index is performing better, while a lower ratio indicates underperformance.

$\mathrm{RR}$ (1952) replaces the risk-free rate with the reserve rate to meet the minimum return rate for the investors, and it is denoted by $\mathrm{R}_{\mathrm{L}, \mathrm{t}}$. It is calculated through:

$$
\mathrm{RR}=\frac{\mathrm{R}_{\mathrm{i}, \mathrm{t}}-\mathrm{R}_{\mathrm{L}, \mathrm{t}}}{\sigma_{\mathrm{i}, \mathrm{t}}}
$$

The RR has an adjustment for the minimum return rate compared with the SR, which uses the risk-free rate to calculate the excess return, and it allows investors to make an optimal choice based on their preference. 


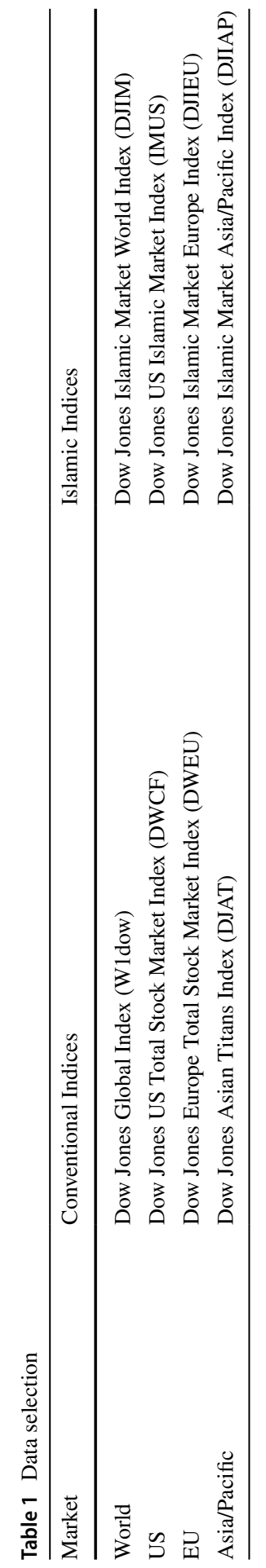


The TR or reward-to-volatility ratio evaluates the average return excess per unit of market risk, which is similar to the SR except for the denominator. TR chooses a denominator by $\beta_{\mathrm{i}}$ which denotes the sensitivity of investment $i$ to the change in the whole market. It calculates the index performance by the given systematic risk level through:

$$
\begin{aligned}
\mathrm{TR} & =\frac{\mathrm{R}_{\mathrm{i}, \mathrm{t}}-\mathrm{R}_{\mathrm{f}, \mathrm{t}}}{\beta_{\mathrm{i}}}, \\
\beta_{i} & =\frac{\operatorname{COV}\left(\mathrm{R}_{\mathrm{i}, \mathrm{t}}, \mathrm{R}_{\mathrm{M}, \mathrm{t}}\right)}{\sigma_{\mathrm{M}, \mathrm{t}}^{2}}
\end{aligned}
$$

where $\beta_{\mathrm{i}}$ is calculated by the covariance between the return of investment $i$ and the return of the market and divided by the variance of the market. In real cases, the higher TR is better than the lower one meaning it has a higher risk-adjusted return.

Although the SR and TR are used to evaluate performance comparisons, both have limits, since they are conducted from the balance sheet. Therefore, this study also utilises the Jensen's Alpha (JA) to evaluate the performance for both indices.

As for the empirical process: firstly, descriptive statistics for the Islamic and conventional indices are estimated for each sample group in different sub-periods. Secondly, financial ratios are compared to evaluate the performance of each index. Moreover, since financial investors seek an investment opportunity to maximize their return which requires lower risk and relatively high return, to analyse the return performance through econometric analysis, Augmented Dickey-Fuller (ADF) (see "Appendix" for full results) test was utilized to test the unit root to ensure both stock returns are not stationary. Capital Asset Pricing Model (CAPM) is widely used in financial analysis to adjust the investment risk, which is also widely used in previous studies to evaluate index performance. For example, Ho et al. (2014) utilized CAPM to examine the Islamic and conventional indices for five sub-periods with the global indices. The evaluation of CAPM by OLS incurs the limitation that the hypotheses are commonly not satisfied by using financial and economic datasets. In responding to this, Jawadi et al. (2014) then improved CAPM-OLS by using exponential Generalized Auto Regressive Conditional Heteroscedasticity (EGARCH), which constitutes the thrust of the main empirical model used in this study.

The CAPM was developed by Sharpe (1966), Lintner (1965) and Mossin (1966), including several derivative ratios, SR and TR and JA. CAPM shows the relationship between the expected return of an asset and its systematic risk, measured by ( $\beta$ ). CAPM is empirically tested using Eq. 5 (Terraza \& Mestre, 2020):

$$
\mathrm{R}_{\mathrm{i}, \mathrm{t}}-\mathrm{R}_{\mathrm{f}, \mathrm{t}}=\alpha+\beta_{\mathrm{i}}\left(\mathrm{R}_{\mathrm{M}, \mathrm{t}}-\mathrm{R}_{\mathrm{f}, \mathrm{t}}\right)+\varepsilon_{\mathrm{t}}
$$

where $R_{i, t}$ is the return on the asset $i$ at time $t$ and $R_{f, t}$ is the risk-free rate at time $t$, $\beta_{i}=\frac{\operatorname{COV}\left(R_{i, t} R_{M, t}\right)}{\sigma_{M, t}^{2}}$ which is the correlation between the return of asset $i$ and the return of the market, $\left(R_{m, t}\right)-R_{f, t}$ is the excess return on the market portfolio and $\varepsilon_{t}$ denotes the error term at time $t$. 
JA (1968) measures the abnormal return of the investment or portfolio over the theoretical expected return under the market risk. A positive JA means the portfolio/ investment outperforms the market. Hence, JA $(\alpha)$ is estimated through Eq. 6:

$$
\alpha=\mathrm{R}_{\mathrm{i}, \mathrm{t}}-\mathrm{R}_{\mathrm{f}, \mathrm{t}}-\beta_{\mathrm{i}}\left(\mathrm{R}_{\mathrm{M}, \mathrm{t}}-\mathrm{R}_{\mathrm{f}, \mathrm{t}}\right)-\varepsilon_{\mathrm{t}}
$$

where $\varepsilon_{t}$ denotes the error term, $\beta_{\mathrm{i}}$ is the correlation between the return of investment and the market and $R_{i, t}, R_{f, t}$ and $R_{M, t}$ denotes the return for the investment, riskfree asset and the market respectively.

Following from Eq. 6, the extended part from the original CAPM, namely, the EGARCH model, is utilized to evaluate the volatility of both indices, which is developed by Bollerslev (1986). Assumptions of no autocorrelation and homoscedasticity of the residuals are often violated which render OLS coefficient estimates not BLUE, however, estimating the CAPM with GARCH/EGARCH errors account for these problems, namely autocorrelation and homoscedasticity in residuals (Terraza \& Mestre, 2020). The GARCH model evaluates the index return, and the risk at the same time, which provides an accurate analysis of the indices' performance. EGARCH, as a part of GARCH, has the extra advantage of accounting for the leverage effect; asymmetric reaction of volatility to positive and negative shocks and to shocks of different sizes, which is commonly appeared in financial data (Jawadi et al, 2014). According to Jawadi et al. (2014), the OLS method applied in CAPM is commonly violated by the extreme volatility, and the CAPM-EGARCH model reduces the bias from the former model.

The range of ARCH and GARCH is broad, while GARCH $(1,1)$ is more efficient to evaluate volatility when compared to the others (Jawadi et al., 2014). Bollerslev (1986) supposes the GARCH $(1,1)$ model explains the structure of the errors, as in Eq. 6:

$$
\varepsilon_{\mathrm{t}}=\mathrm{Z}_{\mathrm{t}} \sqrt{\mathrm{h}_{\mathrm{t}}}, \quad \text { with } \quad \mathrm{h}_{\mathrm{t}}=\theta_{0}+\theta_{1} \varepsilon_{\mathrm{t}-1}^{2}+\varphi_{1} \mathrm{~h}_{\mathrm{t}-1}
$$

where $\theta_{1}>0, \varphi_{1}>0, \theta_{1}+\varphi_{1}<1, \mathrm{E}\left(\mathrm{Z}_{\mathrm{t})}=0\right.$ and $\mathrm{V}\left(\mathrm{Z}_{\mathrm{t})}=\sigma_{\mathrm{t}}^{2}\right.$

According to Jawadi et al. (2014), to avoid asymmetric effects, exponential GARCH (EGARCH) empowers to react with different shocks. Therefore, we can obtain the robust estimator for JA through CAPM-EGARCH $(1,1)$ as follows:

$$
\begin{aligned}
\mathrm{R}_{\mathrm{i}, \mathrm{t}}-\mathrm{R}_{\mathrm{f}, \mathrm{t}} & =\alpha+\beta_{\mathrm{i}}\left(\mathrm{R}_{\mathrm{M}, \mathrm{t}}-\mathrm{R}_{\mathrm{f}, \mathrm{t}}\right)+\varepsilon_{\mathrm{t}} \\
\varepsilon_{\mathrm{t}} & =\mathrm{Z}_{\mathrm{t}} \sqrt{\mathrm{h}_{\mathrm{t}}}
\end{aligned}
$$

In addition, from Eq. (8), the logarithm function of the variance is required to be satisfied in an EGARCH specification. Thus, the assumption of a positive volatility is not necessarily met under the GARCH parameters.

$$
\begin{aligned}
& \log \left(\operatorname{Var}\left[\varepsilon_{\mathrm{t}}\left|\varepsilon_{\mathrm{t}-1}\right|\right]\right)=\log \left(\sigma_{\mathrm{t}}^{2}\right)=\log \left(\mathrm{h}_{\mathrm{t}}\right) \\
& =\omega+\gamma \mathrm{Z}_{\mathrm{t}-1}+\theta_{1}\left(\left|\mathrm{Z}_{\mathrm{t}-1}\right|-\mathrm{E}\left|\mathrm{Z}_{\mathrm{t}-1}\right|\right)+\varphi_{1} \log \left(\mathrm{h}_{\mathrm{t}-1}\right)
\end{aligned}
$$




\section{Empirical Findings}

\subsection{The World Market}

As depicted in Table 2, in the first sub-period, Islamic indices demonstrated higher average return ratios compared with their conventional counterpart, but both are negative and illustrate similar standard deviations. In the second sub-period, Islamic and conventional indices yield the same level average return ratios and standard deviations, indicating risk levels. In third period, Islamic indices have slightly higher average return ratios and lower standard deviations compared with their conventional counterpart. Overall, the average return ratio for Islamic and conventional indices are negative only in the financial crisis period and peaked in the second period. Nevertheless, even they illustrate similar standard deviation for the whole period, while the standard deviation kept decreasing from 2007 to 2017.

Concerning the world market, in Table 3, during the first sub-period, both Islamic and conventional indices demonstrate a negative SR at a similar level, around -0.54 , which means under each unit of risk, their loss ratio is 0.54 . The RR for Islamic indices is slightly higher than the benchmark but is still negative. As for the TR, both offer similar negative figures, -0.0235 and -0.0232 , respectively. In the second sub-period, all ratios for Islamic indices and the benchmark reverse are positive and both appear at a similar level. In the third sub-period, Islamic indices outperform on all ratios compared with the conventional indices.

Three ratios keep increasing from a negative estimation during the financial crisis period until the late post-crisis period. In the first two sub-periods, both Islamic and conventional indices show a similar ratio, except for the RR in the first period. By contrast, in the third sub-period, Islamic indices perform much better when compared to the benchmark, in all aspects.

For further performance comparison, the ADF (see "Appendix") test was utilized to examine the sample of a world market, which is followed by the

Table 2 Comparative descriptive statistics for the world market

\begin{tabular}{lccccccc}
\hline & Mean & Median & SD & Min & Max & Skewness & Kurtosis \\
\hline 2007-2009 & & & & & & & \\
Islamic & -0.0035 & -0.003 & 0.0408 & -0.2121 & 0.1076 & -1.1607 & 9.0393 \\
Benchmark & -0.0047 & 0.0005 & 0.043 & -0.2211 & 0.1151 & -1.1571 & 8.5533 \\
Treasury bill & 0.0184 & 0.0169 & 0.0151 & 0.0001 & 0.0482 & 0.5037 & 2.0315 \\
2009-2013 & & & & & & & 4.9846 \\
Islamic & 0.0019 & 0.0039 & 0.0241 & -0.0917 & 0.0779 & -0.5527 & 4.9129 \\
Benchmark & 0.002 & 0.0036 & 0.0244 & -0.0916 & 0.0795 & -0.5629 & 1.888 \\
Treasury bill & 0.001 & 0.0009 & 0.0005 & 0.0001 & 0.0019 & 0.0364 & \\
2013-2017 & & & & & & & 4.7445 \\
Islamic & 0.0015 & 0.0023 & 0.0155 & -0.0632 & 0.0361 & -0.6415 & 4.4256 \\
Benchmark & 0.0013 & 0.002 & 0.0159 & -0.063 & 0.0422 & -0.5144 & 5.0051 \\
Treasury bill & 0.0019 & 0.0006 & 0.0024 & -0.0001 & 0.0101 & 1.6135 & \\
\hline
\end{tabular}


Table 3 Comparative ratio analysis for the world market

\begin{tabular}{llll}
\hline & SR & RR & TR \\
\hline 2007-2009 & & & \\
Islamic & -0.5375 & -0.0855 & -0.0235 \\
Benchmark & -0.5386 & -0.11 & -0.0232 \\
2009-2013 & & & \\
Islamic & 0.0265 & 0.0802 & 0.0007 \\
Benchmark & 0.027 & 0.08 & 0.0007 \\
2013-2017 & & & \\
Islamic & 0.078 & 0.0983 & 0.0013 \\
Benchmark & 0.0624 & 0.0823 & 0.001 \\
\hline
\end{tabular}

CAPM-EGARCH model to estimate JA and beta of the Islamic index. As can be seen in Table 4, JA indicates the excess return of the Islamic index over the conventional index on a risk-adjusted basis. During the financial crisis period, $\mathrm{JA}$ of the Islamic index is 0 , which means there is no excess return for Islamic indices compared with the benchmark, namely conventional indices (which by default has a JA of zero). In addition, the beta of the Islamic index, which measures its systematic risk, is 0.9362, compared with a beta of 1 for the conventional index (benchmark). In the second sub-period, the alpha of the Islamic index has decreased to -0.0001 . Since the excess return is negative during this period, the conventional indices yield better performance. Concerning beta of the Islamic index during this second period, it becomes 0.9702. In the third subperiod, Islamic indices outperform the conventional ones, since alpha increases to 0.0004 and is significant at $10 \%$ level. The results also show that beta increases to 0.9857. Overall, during the financial crisis, there is no excess return for Islamic index, but it outperforms the conventional index in the third period. For the systematic risk of the Islamic index, it has increased after the financial crisis.

Table 4 Jensen's alpha and beta for the world market Islamic Index

\begin{tabular}{lcc}
\hline & $\begin{array}{l}\text { Alpha } \\
(\text { std })\end{array}$ & $\begin{array}{l}\text { Beta } \\
(\text { std })\end{array}$ \\
\hline $2007-2009$ & 0 & $0.9362 * * *$ \\
$2009-2013$ & $(0.0007)$ & $(0.0125)$ \\
$2013-2017$ & -0.0001 & $0.9702 * * *$ \\
& $(0.0002)$ & $(0.008)$ \\
& $0.0004 *$ & $0.9857 * * *$ \\
& $(0.0002)$ & $(0.0122)$ \\
\hline
\end{tabular}

The conventional index (benchmark) has a Jensen's alpha of zero and a beta of 1. Figures in brackets present the standard error $* * * * * *$ Significance at $1 \%, 5 \%$ and $10 \%$ levels, respectively 
Table 5 Comparative descriptive statistics for the US market

\begin{tabular}{lccccccc}
\hline & Mean & Median & SD & Min & Max & Skewness & Kurtosis \\
\hline 2007-2009 & & & & & & & \\
Islamic & -0.0034 & -0.0006 & 0.0381 & -0.1939 & 0.1019 & -0.956 & 8.5277 \\
Benchmark & -0.0049 & -0.0028 & 0.0428 & -0.1987 & 0.1207 & -0.6101 & 6.8599 \\
Treasury bill & 0.0186 & 0.0169 & 0.0151 & 0.0001 & 0.0482 & 0.492 & 2.0245 \\
2009-2013 & & & & & & & 4.2944 \\
Islamic & 0.0026 & 0.0033 & 0.0234 & -0.0795 & 0.0712 & -0.3474 & 4.216 \\
Benchmark & 0.0029 & 0.0028 & 0.0241 & -0.0819 & 0.0737 & -0.3301 & 4.892 \\
Treasury bill & 0.001 & 0.001 & 0.0005 & 0.0001 & 0.0019 & 0.0179 & 1.7135 \\
2013-2017 & & & & & & & 4.5455 \\
Islamic & 0.0019 & 0.0022 & 0.0165 & -0.0638 & 0.0452 & -0.7076 & 4.7135 \\
Benchmark & 0.0019 & 0.0032 & 0.0163 & -0.0639 & 0.0422 & -0.6208 & 4.52 \\
Treasury bill & 0.0019 & 0.0006 & 0.0024 & -0.0001 & 0.0101 & 1.6207 & 5.0305 \\
\hline
\end{tabular}

Table 6 Comparative ratio analysis for the US market

\begin{tabular}{llll}
\hline & SR & RR & TR \\
\hline 2007-2009 & & & \\
Islamic & -0.5771 & -0.0882 & -0.0253 \\
Benchmark & -0.5487 & -0.1143 & -0.0235 \\
2009-2013 & & & \\
Islamic & 0.0565 & 0.1121 & 0.0014 \\
Benchmark & 0.0678 & 0.1217 & 0.0016 \\
2013-2017 & & & \\
Islamic & 0.098 & 0.1172 & 0.0016 \\
Benchmark & 0.0965 & 0.1159 & 0.0016 \\
\hline
\end{tabular}

\subsection{The US Market}

Table 5 shows that between 2007 and 2009, the average return ratio for Islamic indices is higher than the conventional indices (benchmark) and both are negative in the US market. The standard deviation shows that Islamic indices have less risk attached than conventional indices. Between 2009 and 2013, Islamic indices reverse the condition, showing a lower average return ratio when compared to conventional indices, which yield similar risk levels. From 2013 to 2017, both indices present the same level average return ratios and the same risk. As can be seen, for the whole period, the average return ratio for Islamic and conventional indices are negative during the financial crisis, then peak during 2009 and 2013. It seems that the risk is decreased dramatically from 2007 to 2017.

Table 6 shows that during the financial crisis, both indices yield a negative SR of -0.5771 and -0.5481 , for both Islamic and conventional indices. Islamic indices demonstrate a higher RR compared to their conventional counterpart, -0.0882 and 
-0.1143 , respectively. TR reveals both sets of indices yielding similar levels, around -0.025. During 2009-2013, the Islamic index still demonstrated slightly lower SR, $\mathrm{RR}$ and TR, when compared with conventional indices, although they all increased as positive during this period, $0.0565,0.1121$ and 0.0014 , respectively. In the third sub-period, the condition changed, as Islamic indices show a positive trend. Islamic indices, however, demonstrated both higher SR and RR, when compared to conventional indices, while TR remain the same. Overall, all ratios are negative during the financial crisis, and the SR increases for both indices. After the financial crisis, the $\mathrm{RR}$ and TR remain stable for both indices.

The results from the CAPM-EGARCH model are depicted in Table 7, which present the JA and beta of the Islamic index in the three sub-periods. During the financial crisis period (July 2007 and June 2009), JA is - 0.0007 and significant at a $10 \%$ level, which means the Islamic indices underperform the benchmark (i.e. the conventional index, which has, by default, a JA of zero). In addition, beta of the Islamic index is 0.8698 , compared with the conventional index (benchmark) beta of 1 . After the financial crisis, between 2009 and 2013, although alpha of the Islamic index increases slightly to -0.0005 , its beta increases to 0.9668 . Between 2013 and 2017, alpha of the Islamic index becomes positive, 0.0002, and its beta increased to 0.993 .

Overall, Table 7, shows that following the financial crisis the Islamic index alpha constantly increases from -0.0007 to 0.0002 , while its standard deviation keeps decreasing, which means the excess return notifies a positive trend and is stabilized. For the beta, it also shows the systematic risk is increasing for the Islamic indices compared with the benchmark (conventional index), and, as shown, the standard deviation for beta kept decreasing, which means it is more stable at the end of the whole period.

\subsection{The European Market}

As Table 8 depicts, despite recording similar standard deviation, the average return ratio for both Islamic and conventional indices in the European market are negative, while the former one is higher. However, between 2009 and 2013, the average

Table 7 Jensen's alpha and beta for the US market Islamic Index

\begin{tabular}{lcc}
\hline & $\begin{array}{l}\text { Alpha } \\
(\mathrm{std})\end{array}$ & $\begin{array}{l}\text { Beta } \\
(\mathrm{std})\end{array}$ \\
\hline $2007-2009$ & $-0.0007 *$ & $0.8698 * * *$ \\
& $(0.0004)$ & $(0.0141)$ \\
$2009-2013$ & $-0.0005 * *$ & $0.9668 * * *$ \\
$2013-2017$ & $(0.0002)$ & $(0.0119)$ \\
& 0.0002 & $0.993 * * *$ \\
& $(0.0002)$ & $(0.0104)$ \\
\hline
\end{tabular}

The conventional index (benchmark) has a Jensen's alpha of zero and a beta of 1. Figures in brackets present the standard error $* * * * * *$ Significance at $1 \%, 5 \%$ and $10 \%$ levels, respectively 
Table 8 Comparative descriptive statistics for the European market

\begin{tabular}{lccccccc}
\hline & Mean & Median & SD & Min & Max & Skewness & Kurtosis \\
\hline 2007-2009 & & & & & & & \\
Islamic & -0.0049 & -0.0022 & 0.0503 & -0.2491 & 0.1414 & -1.0607 & 8.0452 \\
Benchmark & -0.0063 & -0.0051 & 0.0521 & -0.2625 & 0.1367 & -1.1928 & 8.2696 \\
Treasury bill & 0.0186 & 0.0169 & 0.0151 & 0.0001 & 0.0482 & 0.492 & 2.0245 \\
2009-2013 & & & & & & & \\
Islamic & 0.0017 & 0.0042 & 0.0294 & -0.1216 & 0.0923 & -0.7009 & 5.3131 \\
Benchmark & 0.0013 & 0.0035 & 0.0318 & -0.1431 & 0.0937 & -0.7577 & 5.3661 \\
Treasury bill & 0.001 & 0.001 & 0.0005 & 0.0001 & 0.0019 & 0.0179 & 1.892 \\
2013-2017 & & & & & & & 3.3577 \\
Islamic & 0.0011 & 0.0023 & 0.018 & -0.0645 & 0.047 & -0.2976 & 3.2 \\
Benchmark & 0.0008 & 0.0019 & 0.0192 & -0.0645 & 0.0506 & -0.3113 & 3.2 \\
Treasury bill & 0.0019 & 0.0006 & 0.0024 & -0.0001 & 0.0101 & 1.6207 & 5.0305 \\
\hline
\end{tabular}

return ratio for Islamic indices is still higher than the conventional indices implying a shouldering of less risk.

In the third sub-period, the average return ratio for Islamic indices retains the previous condition compared with conventional indices. When comparing three subperiods together, Islamic indices yield better performance compared with the benchmark. The average return ratio for both Islamic and conventional indices are negative during the financial crisis and peak in the second period, which drops slightly during the third period. Then, the standard deviation for both indices is decreased dramatically over the whole period.

As detailed in Table 9, between 2007 and 2009, SR is negative both for Islamic indices and their conventional counterpart, while the conventional indices performed slightly lower at -0.04679 and -0.4775 , respectively. For the RR, the sampled indices have produced similar results: the RR for Islamic indices is -0.0979 and the conventional one records -0.1201 . For, the TR, they are at the same level at -0.0249. Between 2009 and 2013, for the SR, Islamic indices kept its trend at a

Table 9 Comparative ratio analysis for the European market

\begin{tabular}{llll}
\hline & $\mathrm{SR}$ & $\mathrm{RR}$ & $\mathrm{TR}$ \\
\hline 2007-2009 & & & \\
Islamic & -0.4679 & -0.0979 & -0.0249 \\
Benchmark & -0.4775 & -0.1201 & -0.0249 \\
2009-2013 & & & \\
Islamic & 0.0121 & 0.0563 & 0.0004 \\
Benchmark & 0.0002 & 0.0411 & 0 \\
2013-2017 & & & \\
Islamic & 0.042 & 0.0597 & 0.0008 \\
Benchmark & 0.0249 & 0.0415 & 0.0005 \\
\hline
\end{tabular}


higher ratio, but both increased to 0.0121 and 0.0002 . The RR for both Islamic and conventional indices kept the same scenario as the SR, whereby, they both increased to 0.0563 and 0.0411 , respectively. During this period, Islamic indices have a slightly higher TR at 0.0004 and the conventional one increased from -0.00249 to 0 . Between 2013 and 2017, these three ratios for both indices kept increasing and the performance of Islamic indices was higher than the conventional counterpart for all ratios, as SR for Islamic and conventional indices increased to 0.042 and 0.0249 , respectively. For the RR, they increase to 0.0597 and 0.0415 , respectively, while the TR increases slightly to 0.0008 and 0.005 , respectively.

During the financial crisis, both Islamic and conventional indices showed a negative result in the case of these three ratios. After the financial crisis, all three of the ratios became positive and kept increasing. Islamic indices outperform conventional ones in the case of the three ratios during the financial crisis and non-crisis period.

Table 10 presents the CAPM-EGARCH model estimates of the JA and beta of the Islamic index for the three sub-periods. The convectional index has a JA of zero and beta of 1 . In the first sub-period, JA of the Islamic index is 0.0007 , while its beta is 0.9777. However, in the second sub-period, alpha and beta both decrease to 0.0004 and 0.912, respectively, while in the third sub-period, alpha and beta kept decreasing to 0.0002 and 0.0944 , respectively. The results show that after the financial crisis, alpha of the Islamic index keeps decreasing from 0.0007 to 0.0002 but remains positive. Concerning the systematic risk of the Islamic index, beta shows a negative trend after the financial crisis.

\subsection{The Asia-Pacific Markets}

The results for the Asia-Pacific market are detailed in Table 11, which shows a clear average return ratio and standard deviation in three sub-periods. During the financial crisis, Islamic indices yield a slightly high negative average return ratio compared with their conventional counterpart, and they illustrate a similar risk. Between 2009 and 2013, the average return ratio for Islamic indices and the conventional indices both increase to 0.0012 and 0.001 , respectively and the standard deviation decreases

Table 10 Jensen's alpha and beta for the European market Islamic Index

\begin{tabular}{lcc}
\hline & $\begin{array}{l}\text { Alpha } \\
(\mathrm{std})\end{array}$ & $\begin{array}{l}\text { Beta } \\
(\mathrm{std})\end{array}$ \\
\hline $2007-2009$ & 0.0007 & $0.9777 * * *$ \\
& $(0.0011)$ & $(0.0177)$ \\
$2009-2013$ & 0.0004 & $0.912 * * *$ \\
$2013-2017$ & $(0.0004)$ & $(0.0097)$ \\
& 0.0002 & $0.9044 * * *$ \\
& $(0.0004)$ & $(0.016)$ \\
\hline
\end{tabular}

The conventional index (benchmark) has a Jensen's alpha of zero and a beta of 1 . Figures in brackets present the standard error $* * *, * *, *$ Significance at $1 \%, 5 \%$ and $10 \%$ levels, respectively 
Table 11 Comparative descriptive statistics for the Asia-Pacific markets

\begin{tabular}{lcclllll}
\hline & Mean & Median & SD & Min & Max & Skewness & Kurtosis \\
\hline 2007-2009 & & & & & & & \\
Islamic & -0.0037 & -0.0032 & 0.0423 & -0.199 & 0.1067 & -0.911 & 6.5754 \\
Benchmark & -0.0043 & 0.0008 & 0.043 & -0.1922 & 0.084 & -0.8119 & 5.5053 \\
Treasury bill & 0.0186 & 0.0169 & 0.0151 & 0.0001 & 0.0482 & 0.492 & 2.0245 \\
2009-2013 & & & & & & & 4.7277 \\
Islamic & 0.0012 & 0.0018 & 0.024 & -0.089 & 0.075 & -0.5121 & 4.2038 \\
Benchmark & 0.001 & 0.0023 & 0.0255 & -0.0845 & 0.087 & -0.2898 & 1.892 \\
Treasury bill & 0.001 & 0.001 & 0.0005 & 0.0001 & 0.0019 & 0.0179 & \\
2013-2017 & & & & & & & 4.3253 \\
Islamic & 0.0014 & 0.0019 & 0.0169 & -0.0584 & 0.0537 & -0.2848 & 4.9193 \\
Benchmark & 0.0006 & 0.0017 & 0.0201 & -0.0781 & 0.0628 & -0.072 & 5.0305 \\
Treasury bill & 0.0019 & 0.0006 & 0.0024 & -0.0001 & 0.0101 & 1.6207 & 5 \\
\hline
\end{tabular}

to 0.024 and 0.0255 , respectively. Between 2013 and 2017, the average return ratio for Islamic indices increased from 0.0012 to 0.0014 , while the conventional one decreases from 0.001 to 0.0006 . During this period, the standard deviation for both indices kept decreasing. Overall, the main trend for the average return ratio for both indices kept increasing from -0.0037 and -0.0043 in the financial crisis period to 0.0014 and 0.0006 in 2017, respectively. Meanwhile, the standard deviation for both indices decreased dramatically.

As can be seen from CAPM-EGARCH model in Table 12, between 2007 and 2009, Islamic and conventional indices remained at a similar level within the SR, namely -0.0527 and -0.05322 , and the TR, at -0.0238 and 0.0229 , respectively. For RR, Islamic indices were slightly higher than the conventional indices, at -0.0873 and -0.0994, respectively. Between 2009 and 2013, Islamic and conventional indices retained similar levels for both the SR and TR, while both increased to around 0. During this period, Islamic indices still had a higher RR than their counterpart, at 0.0482 and 0.0401, respectively. Between 2013 and 2017, the three ratios

Table 12 Comparative ratio analysis for the Asia-Pacific markets

\begin{tabular}{llll}
\hline & SR & RR & TR \\
\hline 2007-2009 & & & \\
Islamic & -0.527 & -0.0873 & -0.0238 \\
Benchmark & -0.5322 & -0.0994 & -0.0229 \\
2009-2013 & & & \\
Islamic & -0.006 & 0.0482 & -0.0002 \\
Benchmark & -0.011 & 0.0401 & -0.0003 \\
2013-2017 & & & \\
Islamic & 0.0648 & 0.0836 & 0.0014 \\
Benchmark & 0.015 & 0.0308 & 0.0003 \\
\hline
\end{tabular}


for Islamic indices increased faster than for the conventional indices. The SR for Islamic and conventional indices were 0.0648 and 0.015 , respectively, while they were 0.0836 and 0.0308 for the RR, respectively. For the TR, they both kept staying around 0 .

During the financial crisis period, Islamic indices and their conventional counterparts operated at similar levels for both the SR and TR, although the former illustrates a higher TR. It is important to state that after the financial crisis, even though all the ratios kept increasing for both indices, Islamic indices increase at a faster rate, and shows the improved performance at the end of the final sub-period.

In further examining the comparison between Islamic and conventional indices in the Asia-Pacific market, following the ADF test (as depicted in the "Appendix"), the JA and beta of the Islamic index were estimated through CAPM-EGARCH model. As can be seen in Table 13 for three sub-periods for the Asia-Pacific market, between 2007 and 2009, the alpha score is - 0.0007, which indicates the excess return for Islamic index compared with conventional indices. At the same time, beta of the Islamic index records 0.9482 , compared with a beta of 1 for the conventional index. After the financial crisis, between 2009 and 2013, the Islamic index alpha increases to 0, while beta decreases to 0.8957. Then, between 2013 and 2017, alpha increases to 0.0008 and beta decreases to 0.7866 .

Islamic indices in the Asia-Pacific market demonstrated a better performance following the financial crisis since the excess return kept increasing from -0.0007 in the first sub-period to 0.0008 during the third sub-period. In addition, the systemic risk also records a decrease from 0.9482 to 0.7866 . Overall, Islamic indices outperform conventional indices after the financial crisis.

\subsection{Testing the Differences in Performance}

In order to test the statistical significance of the differences in the performance of Islamic and conventional and Islamic indices, t-test for difference-in-means is applied under each of the three performance ratios-SR, RR and TR - and for the four sampled regions, namely the World (Table 2), the US (5), the EU (Table 8) and Asia-Pacific (Table 11). The analysis is further extended for the mean difference

Table 13 Jensen's alpha and beta for the Asia-Pacific market Islamic Index

\begin{tabular}{lcc}
\hline & $\begin{array}{l}\text { Alpha } \\
(\mathrm{std})\end{array}$ & $\begin{array}{l}\text { Beta } \\
(\mathrm{std})\end{array}$ \\
\hline $2007-2009$ & -0.0007 & $0.9482 * * *$ \\
& $(0.0016)$ & $(0.0241)$ \\
$2009-2013$ & 0 & $0.8957 * * *$ \\
$2013-2017$ & $(0.0006)$ & $(0.0174)$ \\
& 0.0008 & $0.7866^{* * *}$ \\
& $(0.0005)$ & $(0.0238)$ \\
\hline
\end{tabular}

The conventional index (benchmark) has a Jensen's alpha of zero and a beta of 1. Figures in brackets present the standard error $* * *, * *, *$ Significance at $1 \%, 5 \%$ and $10 \%$ levels, respectively 
for the whole period of 2007-2017 and the three sub-periods, namely 2007-2009, 2009-2013, and 2013-2017.

The theoretical expectation based on the Islamic moral economy assumes decoupling hypothesis suggesting that due to the distinguishing nature of Islamic finance, there should be the difference in the performance of Islamic and conventional finance, as Islamic finance should be embedded in the real economy and moral principles (Asutay, 2013, 2015). As shown in Table 14, the results, however, indicate no significant differences in the performance of Islamic and conventional indices as compared between the regions and the sub-period, including the whole period. Hence, contrary to the theoretical expectation, the results provide evidence for the coupling hypothesis suggesting that Shari'ah compliant investments are not isolated from economic and financial developments and shocks affecting the world financial system. This finding is in line, among others, with Ahmed and Elsayed (2019) and Aksak and Asutay (2015).

\subsection{Overall Comparison}

According to the findings presented from Tables 2, 3, 4, 5, 6, 7, 8, 9, 10, 11, 12 and 13, between 2007 and 2009, which constitutes the financial crisis period, the average return for all regions is negative for both Islamic and conventional indices.

During the 2007-2009 period, for Islamic indices, the US market offered the highest average return of -0.0034 and the lowest standard deviation of 0.0381 compared with the other markets. Compared to the benchmark, during this period, Islamic indices outperformed all markets showing a higher return and lower risk. In the second sub-period, Islamic indices in the US market kept the same position, when compared with the other markets. During this period, Islamic indices still show a lower risk than the benchmark in all markets, but the benchmark has a higher average return than Islamic indices for the world and US markets. In the third sub-period, Islamic indices for both world and the US markets both perform well offering average returns of 0.0015 and 0.0019 and a standard deviation: 0.0155 and 0.0165 , respectively. Compared with the benchmark, even overall Islamic indices perform better, but in the world and the US market, they are almost the same.

As for the comparative financial analysis between Islamic and conventional indices in four markets, in the first sub-period, the European market shows the highest $\mathrm{SR},-0.0469$, for Islamic indices. Except for the US market, Islamic indices have a higher SR than the benchmark in the other three markets. As for RR, Islamic indices outperform the benchmark in all four markets. In other words, as can be seen in Table 3, the world market has the highest RR for Islamic indices, which is -0.0855 , while for the TR, there is no significant difference between Islamic indices and the benchmark, but the Asia-Pacific market shows higher figures compared to the others.

In the second sub-period, in the case of the SR, Islamic indices outperform the benchmark only in European and Asia-Pacific markets. To be more specific, as can be seen in Table 9, the European market has the highest SR, 0.0121, and only the Asia-Pacific market, as in Table 12, details a negative SR, -0.006 . With respect 


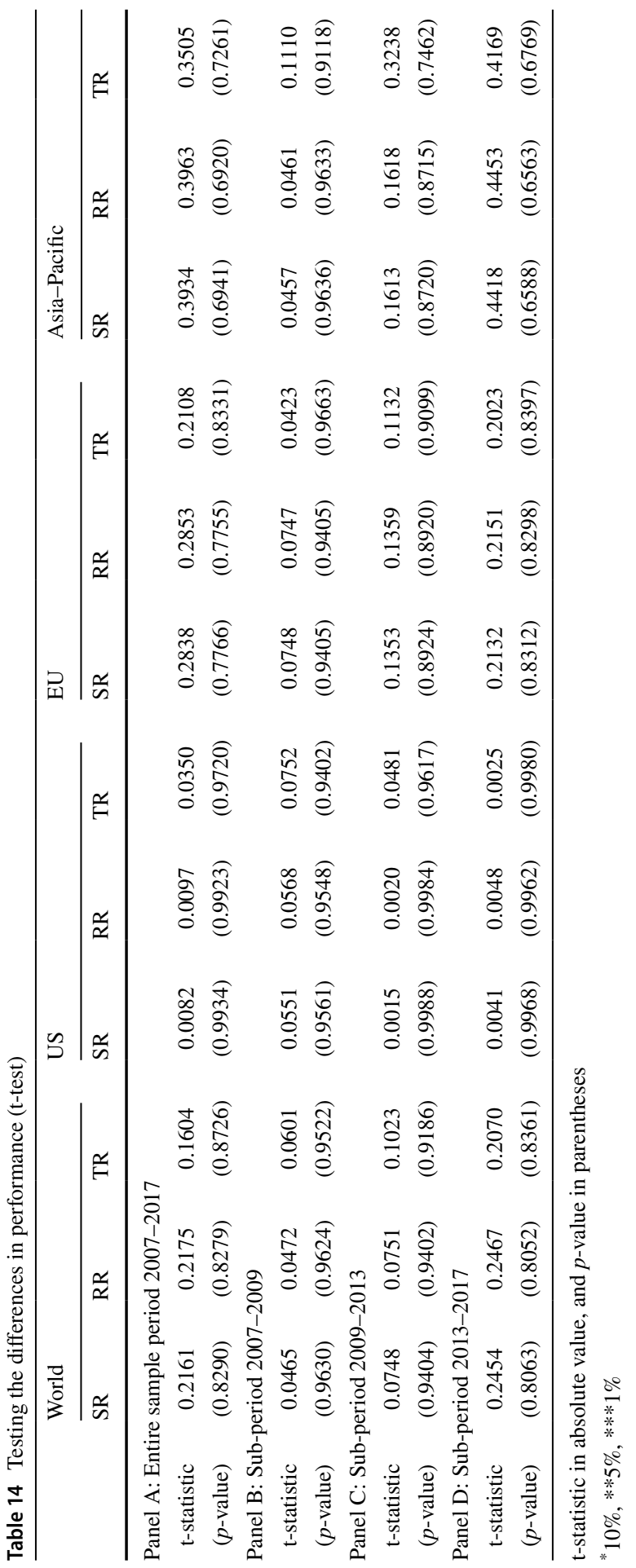


to RR, Islamic indices illustrated a higher RR than the benchmark in all markets, except the US market. Nevertheless, the US market has the highest RR for Islamic indices compared with the other three markets. When it comes to the TR, there is no significant difference between Islamic indices and the benchmark. The indices from the European market yielded the highest figure and only the Asia-Pacific market is negative.

In the third sub-period, for the SR, Islamic indices outperform the benchmark in all markets. Accordingly, the US market has the highest SR for Islamic indices for 0.098 (see Table 6), while the European market and the Asia-Pacific market show that Islamic indices were greater than the benchmark to a large extent. For the $\mathrm{RR}$, the scenario is almost the same as the $\sim$ SR. Finally, for TR, Islamic indices are slightly higher than the benchmark in both the world and Asia-Pacific markets and remain the same in the other two markets, while the US market, as can be seen in Table 6 , shows the highest figure of 0.0016 for Islamic indices.

During these three sub-periods, Islamic indices have a higher SR and RR for the first sub-period, and the third sub-period for all four markets, while there is no significant difference during the second sub-period. As for the TR, there is no clear difference between Islamic indices and the benchmark for all four markets.

As the results through CAPM-EGARCH model are depicted above, in the first sub-period, for JA, Europe retains the highest figure of 0.0007 (see Table 10), while the world market stands in the second position at 0, and the US and Asia-Pacific markets have the same figure: -0.0007 (see Tables 7 and 13, respectively). However, as can be seen in Table 10, the European indices have the highest beta score at 0.9777 , compared to the others.

In the second sub-period, for JA, the European index maintains the highest position at 0.0042 (see Table 8), while the world and Asia-Pacific markets remained at 0 , and the US market was at the bottom with -0.0005 (see Table 7). When it comes to beta, during this period, as can be seen in Table 4, the world market has the highest systematic risk at 0.9702 . The US stands in the second position at 0.9668 (see Table 7), while the European and Asia-Pacific score 0.912 and 0.8957 , respectively (see Tables Table 12 and 13, respectively).

In the third sub-period, for JA, the Asia-Pacific market moves to the top position with 0.0008 (see Table 13). Then, as can be seen from Table 4, the world market records 0.0004 and the others score 0.0002. During this period, the US market yielded the highest systemic risk at 0.993 (see Table 7), while the Asia-Pacific market shows the lowest figure at 0.7866 (see Table 13). The world and European market ratios are 0.9857 (see Table 4) and 0.9044 (see Table 10), respectively.

Overall, JA shows a positive trend from a negative to positive transformation for all markets, except for the European market. Of all the markets, the Asia-Pacific one shows great growth through the three sub-periods. With respect to the systemic risk, the world and the US markets kept increasing during the first sub-period to the third one. In contrast, the European and Asia-Pacific markets recorded a negative trend for the beta. 


\section{Conclusions and Implications}

From the preceding empirical findings, the following implications can be deduced: Firstly, during the global financial crisis (2007-2009), Islamic indices significantly outperformed conventional indices over all four markets to the extent that even during the economic downturn, Islamic indices demonstrated less loss and less risk compared with the conventional indices in all markets. Our finding is also supported by previous studies, such as those offered by Jawadi et al. (2014) and Al-Yahyaee et al. (2020).

Secondly, during the initial years following the financial crisis, namely, the 2009-2013 period, the findings show that there is no significant advantage between Islamic indices and their conventional peer, as they demonstrate a different performance in each market. In other words, comparatively, Islamic indices illustrate a better performance for returns in the European and Asia-Pacific markets and worse performances in the world and the US markets. Nevertheless, Islamic indices show lower risks in all markets during this period, as well.

Thirdly, during the second part of the post-crisis period, namely, the 2013-2017 period, Islamic indices significantly outperformed their conventional counterpart again. In other words, from the comparative descriptive statistics, Islamic indices have a higher average return value and lower standard deviation, which indicates the level of risk. For, the standard ratio comparison and main model, Islamic indices also have a higher value in all the markets.

Although Islamic indices outperformed the conventional indices for all markets during the financial crisis (2007-2009) and in the later years of the post-crisis period (2013-2017), Islamic indices have demonstrated better performance in the European and Asia-Pacific markets compared within the other markets during this period. Islamic indices outperformed their conventional counterpart for all three sub-periods in these two markets. Meanwhile, in the third sub-period, the difference of the value between Islamic indices and the conventional one shows that Islamic indices have more advantage in the European and Asia-Pacific markets. Such a sustained performance will have implications for the sector, as it will attract further investors to the sector regardless of its religious underpinnings. The robust and sustained performance will also help the Islamic finance sector in general and Islamic stock markets, in particular, to gain further legitimacy in its attempt to be further acceptable in the global financial markets.

The study is expected to help policy makers to recognise the benefits of nonconventional indices and their performance in different regions. This can be useful in introducing 'Islamic financing', which defines ethical activities, accounting, and financial screening for different performance outcomes. Investors, especially Muslim investors, are interested to see that investing in Shari'ah compliant investments will help them with their financial gains. This is especially important given the anecdotal evidence of higher costs for Shari'ah compliant investment.

In conclusion, results for all the ratios remain consistent in most cases. However, in entire period sample we obtained mixed results as both conventional and Islamic indices share an overall equal performance position. Using Jensen's Alpha measures, 
the results obtained report the dominant performance of Islamic indices over conventional parts. As evidenced by the results, during the crises period, Islamic indices' performance was better in most cases compared to their conventional counterpart. The findings demonstrate that Islamic indices have a lower risk and a relatively higher return rate when compared to conventional indices. This is attributed to the ethical principles of Islamic finance. However, our findings only explain historical data and cannot guarantee specific results for the future.

The implications for portfolio investors dealing with Islamic and conventional indices is the high return performance and the lower risk compared to conventional during and the latter part of post-crisis period can induce investors to increase investment in Shari'ah compliant instruments based on Islamic philosophy. Our analysis of different indices across different regions provides in depth insight into Islamic financial sector that have a good investment potential during both normal and turbulent periods.

\section{Appendix: Augmented Dickey-Fuller (ADF) Test}

\section{ADF Test Results for World Sample}

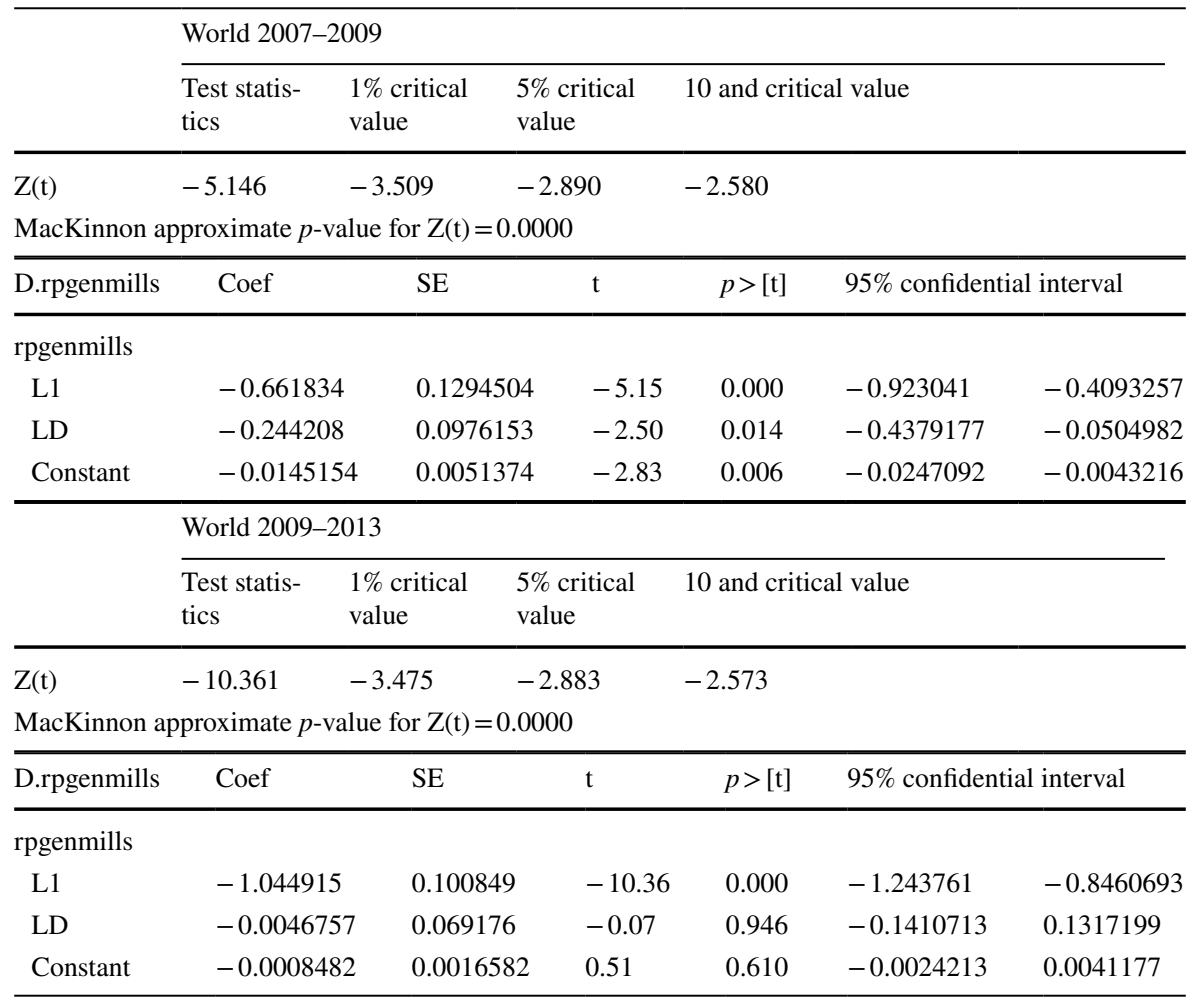




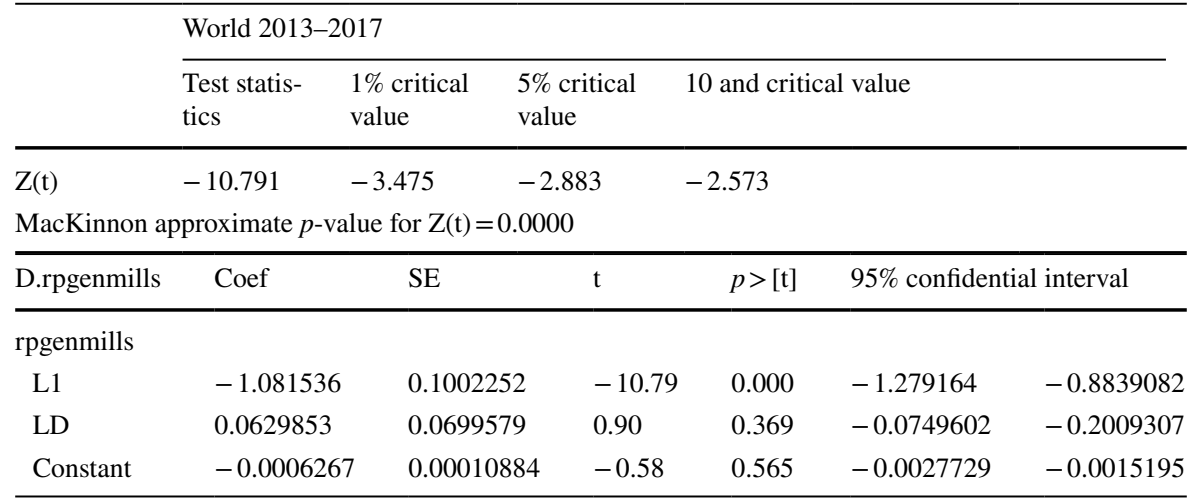

\section{ADF Test Results for the US Sample}

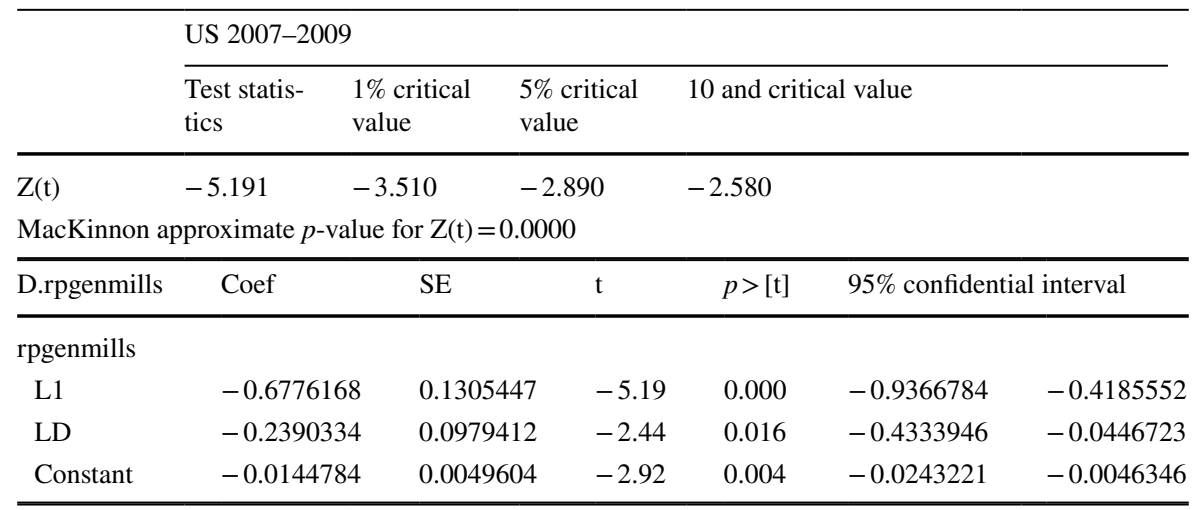

US 2009-2013

\begin{tabular}{lllll}
\cline { 2 - 4 } & $\begin{array}{l}\text { Test statis- } \\
\text { tics }\end{array}$ & $\begin{array}{l}1 \% \text { critical } \\
\text { value }\end{array}$ & $\begin{array}{l}5 \% \text { critical } \\
\text { value }\end{array}$ & 10 and critical value \\
\hline $\mathrm{Z}(\mathrm{t})$ & -10.1776 & -3.475 & -2.883 & -2.573
\end{tabular}

MacKinnon approximate $p$-value for $\mathrm{Z}(\mathrm{t})=0.0000$

\begin{tabular}{lllllll}
\hline D.rpgenmills & Coef & SE & $\mathrm{t}$ & $p>[\mathrm{t}]$ & $95 \%$ confidential interval \\
\hline rpgenmills & & & & & & \\
L1 & -1.095144 & 0.1016308 & -10.78 & 0.000 & -1.295531 & -0.8947567 \\
LD & -0.0196567 & 0.0689716 & 0.28 & 0.776 & -0.1163358 & -0.1556492 \\
Constant & 0.0016023 & 0.0016143 & 0.99 & 0.322 & -0.0015807 & -0.0047852 \\
\hline
\end{tabular}




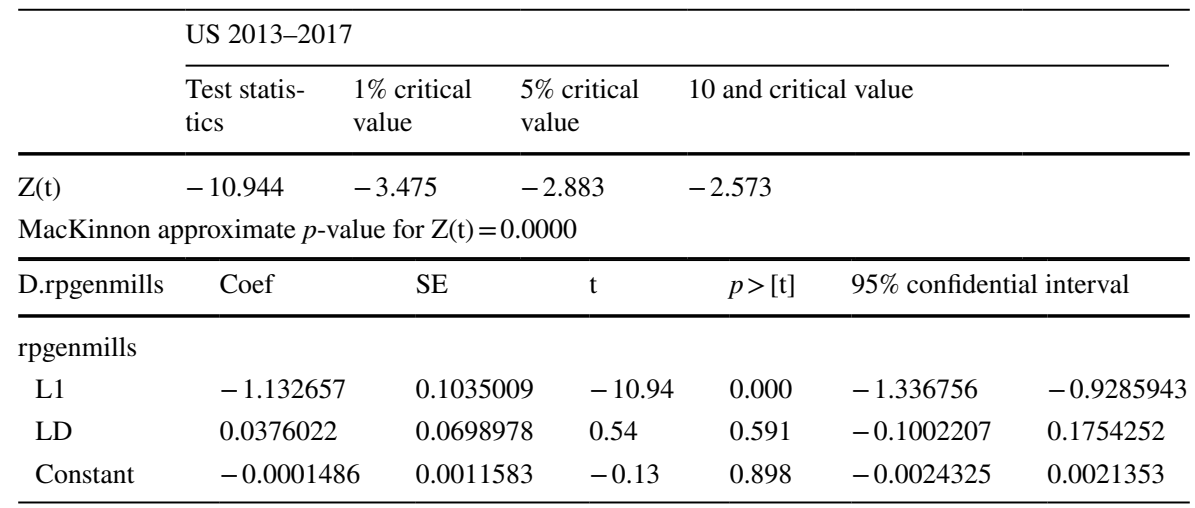

\section{ADF Test Results for the EU Sample}

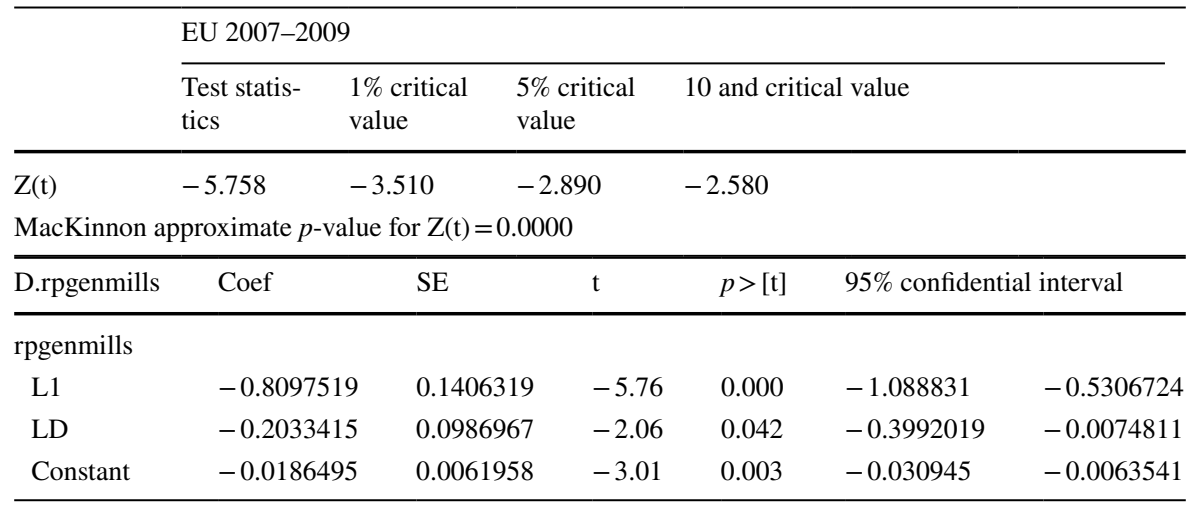

\begin{tabular}{|c|c|c|c|c|c|c|c|}
\hline & \multicolumn{7}{|l|}{ EU 2009-2013 } \\
\hline & $\begin{array}{l}\text { Test statis- } \\
\text { tics }\end{array}$ & $\begin{array}{l}1 \% \text { critical } \\
\text { value }\end{array}$ & \multicolumn{2}{|c|}{$\begin{array}{l}5 \% \text { critical } \\
\text { value }\end{array}$} & \multicolumn{3}{|c|}{$10 \&$ critical value } \\
\hline $\mathrm{Z}(\mathrm{t})$ & -10.444 & -3.475 & & 383 & -2.573 & & \\
\hline \multicolumn{8}{|c|}{ MacKinnon approximate $p$-value for $Z(t)=0.0000$} \\
\hline D.rpgenmills & Coef & SE & & $\mathrm{t}$ & $p>[\mathrm{t}]$ & $95 \%$ confiden & interval \\
\hline \multicolumn{8}{|l|}{ rpgenmills } \\
\hline L1 & -1.060453 & 0.1015 & & -10.44 & 0.000 & -1.260663 & -0.8602432 \\
\hline LD & 0.005008 & 0.0696 & & 0.07 & 0.943 & -0.1323231 & 0.1423391 \\
\hline Constant & 0.0005724 & 0.0020 & & 0.28 & 0.779 & -0.0034357 & 0.0045805 \\
\hline
\end{tabular}




\begin{tabular}{|c|c|c|c|c|c|c|c|c|}
\hline & \multicolumn{8}{|l|}{ EU 2013-2017 } \\
\hline & \multirow{2}{*}{$\begin{array}{l}\begin{array}{l}\text { Test statis- } \\
\text { tics }\end{array} \\
-11.323\end{array}$} & \multicolumn{2}{|c|}{$\begin{array}{l}1 \% \text { critical } \\
\text { value }\end{array}$} & \multicolumn{2}{|c|}{$\begin{array}{l}5 \% \text { critical } \\
\text { value }\end{array}$} & \multicolumn{3}{|c|}{10 and critical value } \\
\hline $\mathrm{Z}(\mathrm{t})$ & & & 475 & & & -2.573 & & \\
\hline \multicolumn{9}{|c|}{ MacKinnon approximate $p$-value for $\mathrm{Z}(\mathrm{t})=0.0000$} \\
\hline D.rpgenmills & Coef & & SE & & $\mathrm{t}$ & $p>[\mathrm{t}]$ & $95 \%$ confiden & interval \\
\hline \multicolumn{9}{|l|}{ rpgenmills } \\
\hline L1 & \multicolumn{2}{|l|}{-1.086389} & \multicolumn{2}{|c|}{0.0959442} & -11.32 & 0.000 & -1.275569 & -0.8972081 \\
\hline $\mathrm{LD}$ & \multicolumn{2}{|l|}{0.1209458} & \multicolumn{2}{|c|}{0.0685918} & -1.76 & 0.079 & -0.014302 & 0.2561936 \\
\hline Constant & \multicolumn{2}{|c|}{-0.0012075} & \multicolumn{2}{|c|}{0.0012366} & -0.98 & 0.330 & -0.0036459 & 0.0012308 \\
\hline
\end{tabular}

\section{ADF Test Results for the Asia-Pacific Sample}

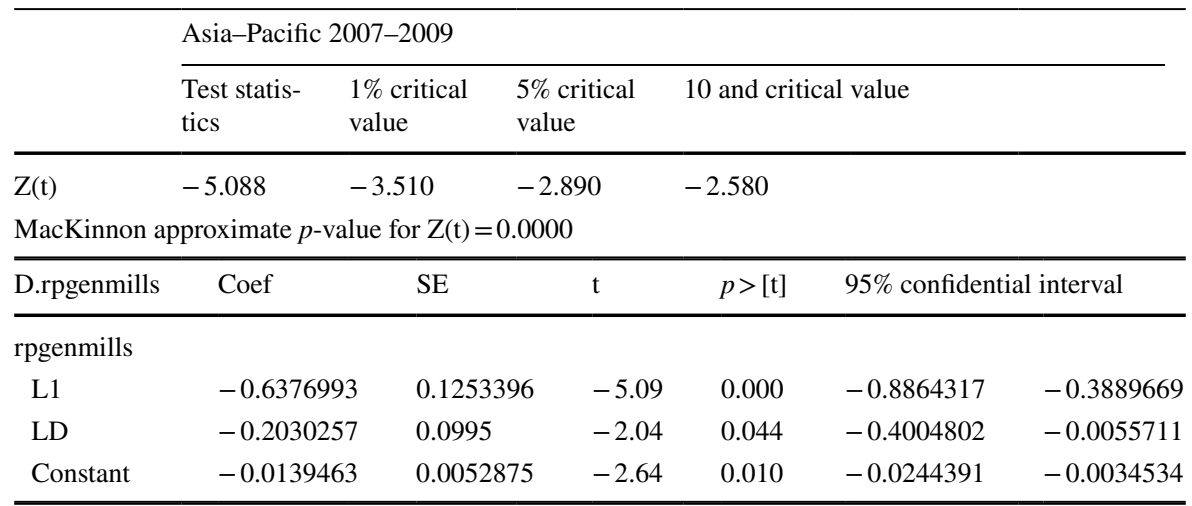

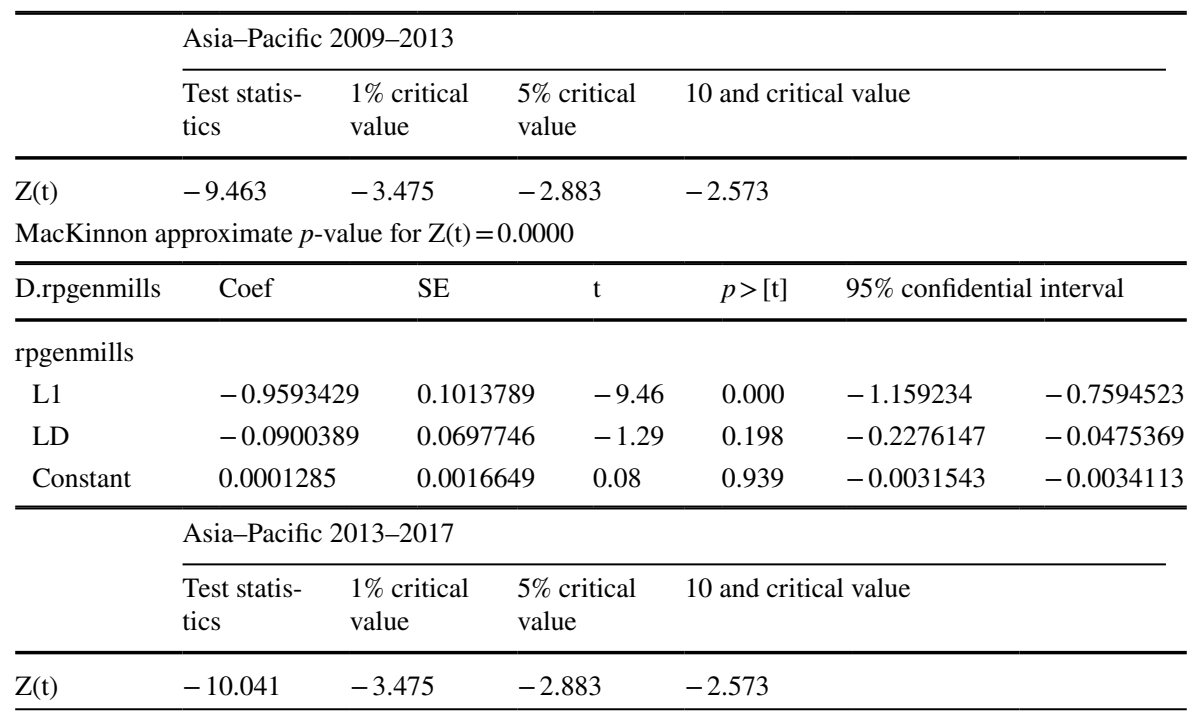


Asia-Pacific 2013-2017

\begin{tabular}{llll}
\hline $\begin{array}{l}\text { Test statis- } \\
\text { tics }\end{array}$ & $\begin{array}{l}1 \% \text { critical } \\
\text { value }\end{array}$ & $\begin{array}{l}5 \% \text { critical } \\
\text { value }\end{array}$ & 10 and critical value \\
\hline
\end{tabular}

\begin{tabular}{lllllll}
\hline \multicolumn{6}{l}{ MacKinnon approximate $p$-value for $\mathrm{Z}(\mathrm{t})=0.0000$} \\
\hline D.rpgenmills & Coef & $\mathrm{SE}$ & $\mathrm{t}$ & $p>[\mathrm{t}]$ & $95 \%$ confidential interval \\
\hline rpgenmills & & & & & & \\
L1 & -1.01443 & 0.1010258 & -10.04 & 0.000 & -1.21363 & -0.8152298 \\
LD & -0.0215502 & 0.0700766 & -0.31 & 0.759 & -0.1597255 & 0.1166252 \\
Constant & -0.0006642 & 0.0011847 & -0.56 & 0.576 & -0.0030002 & 0.0016719 \\
\hline
\end{tabular}

Open Access This article is licensed under a Creative Commons Attribution 4.0 International License, which permits use, sharing, adaptation, distribution and reproduction in any medium or format, as long as you give appropriate credit to the original author(s) and the source, provide a link to the Creative Commons licence, and indicate if changes were made. The images or other third party material in this article are included in the article's Creative Commons licence, unless indicated otherwise in a credit line to the material. If material is not included in the article's Creative Commons licence and your intended use is not permitted by statutory regulation or exceeds the permitted use, you will need to obtain permission directly from the copyright holder. To view a copy of this licence, visit http://creativecommons.org/licen ses/by/4.0/.

\section{References}

Ahmed, H., \& Elsayed, A. H. (2019). Are Islamic and conventional capital markets decoupled? Evidence from stock and bonds/sukuk markets in Malaysia. Quarterly Review of Economoics and Finance, 74, 56-66.

Akguc, S., \& Al Rahahleh, N. (2020). Shariah compliance and investment behavior: Evidence from GCC countries. Emerging Markets Finance and Trade, 57(13), 3766-3791.

Aksak, E., \& Asutay, M. (2015). The Maqasid and the empirics: Has Islamic finance fulfilled its promise? In M. Asutay \& A. Turkistani (Eds.), Islamic finance: Political economy perspectives. Gerlach.

Alahouel, F., \& Loukil, N. (2020). Financial uncertainty valuation: Does Shariah compliant screening matter? International Journal of Islamic and Middle Eastern Finance and Management, 14(1), 57-76.

Albaity, M., \& Mudor, H. (2012). Return performance, cointegration and short-run dynamics of Islamic and non-Islamic indices: Evidence from the US and Malaysia during the subprime crisis. Atlantic Review of Economics, 1(1), 1-22.

Al-Yahyaee, K. H., Mensi, W., Rehman, M. U., Vo, X. V., \& Kang, S. H. (2020). Do Islamic stocks outperform conventional stock sectors during normal and crisis periods? Extreme co-movements and portfolio management analysis. Pacific-Basin Finance Journal, 62, 1-21.

Anwer, Z., Mohamad, S., Paltrinieri, A., \& Hassan, M. K. (2020). Dividend payout policy of Shariah compliant firms: Evidence from United States. Pacific Basin Finance Journal. https://doi.org/10.1016/j.pacfin. 2020.101422

Ashraf, D. (2016). Does Shari'ah screening cause abnormal returns? Empirical evidence from Islamic equity indices. Journal of Business Ethics, 134, 209-228.

Ashraf, D., \& Mohammad, N. (2014). Matching perception with the reality: Performance of Islamic equity investments. Pacific-Basin Finance Journal, 28, 175-189.

Asutay, M. (2013). Islamic moral economy as the foundation of Islamic finance. In V. Cattelan (Ed.), Islamic finance in Europe: Towards a plural financial system. Edward Elgar.

Asutay, M. (2015). Islamic finance: Principles, institutions and development. Trade and Finance, 2015, 4-26.

Bin Mahfooz, S., \& Habib, A. (2014). Shari'ah investment screening criteria: A critical review. JKAU: Islamic Economics, 27(1), 27-38. 
Bollerslev, T. (1986). Generalized autoregressive conditional heteroskedasticity. Journal of Econometrics, 31(3), 307-327.

Cheong, C. W. H. (2021). Risk, resilience, and Shariah-compliance. Research in International Business and Finance., 55, 1-16. https://doi.org/10.1016/j.ribaf.2020.101313

DeLorenzo, Y. (2000). The religious foundations of Islamic finance. The Jurist, 60(1), 137-161.

Derigs, U., \& Marzban, S. (2008). Review and analysis of current Shariah-compliant equity screening practices. International Journal of Islamic and Middle Eastern Finance and Management, 1(4), 285-303.

El Alaoui, A. O., Bacha, O. I., Masih, M., \& Asutay, M. (2016). Shari'ah stock screening, sensitivity to market risk and contagion: A multi-country analysis. Journal of Economic Behavior \& Organization, 132, 93-112.

GIFR. (2018). Global Islamic Finance Report 2018. Edbiz Consulting.

Godil, D. I., Sarwat, S., Sharif, A., Sharif, A., Jermsittiparsert, K., \& Jermsittiparsert, K. (2020). How oil prices, gold prices, uncertainty and risk impact Islamic and conventional stocks? Empirical evidence from QARDL technique. Resources Policy, 66, 1-9.

Hammoudeh, S., Mensi, W., Reboredo, J., \& Nguyen, D. (2014). Dynamic dependence of the global Islamic equity index with global conventional equity market indices and risk factors. Pacific-Basin Finance Journal, 30, 189-206.

Hayat, R., \& Hassan, M. K. (2016). Does an Islamic label indicate good corporate governance? Journal of Corporate Finance, 43, 159-174.

Hayat, R., \& Kraeussl, R. (2011). Risk and return characteristics of Islamic equity funds. Emerging Markets Review, 12(2), 189-203.

Ho, C., Abd Rahman, N., Yusuf, N., \& Zamzamin, Z. (2014). Performance of global Islamic versus conventional share indices: International evidence. Pacific-Basin Finance Journal, 28, 110-121.

IFSB. (2021). Islamic Financial Services Industry Stability Report 2021. IFSB: Kuala Lumpur, Malaysia.

Jawadi, F., Jawadi, N., \& Louhichi, W. (2014). Conventional and Islamic stock price performance: An empirical investigation. International Economics, 137, 73-87.

Kafou, A., \& Chakir, A. (2017). From screening to compliance strategies: The case of Islamic stock indices with application on "MASI." Islamic Economic Studies, 25, 55-84.

Klein, P.-O., Turk, R., \& Weill, L. (2017). Religiosity vs. well-being effects on investor behavior. Journal of Economic Behavior \& Organization, 138, 50-62.

Lintner, J. (1965). The valuation of risk assets and the selection of risky investments in stock portfolios and capital budgets. The Review of Economics and Statistics, 47(1), 13-37.

Mazouz, K., Mohamed, A., \& Saadouni, B. (2016). Stock return co-movement around the Dow Jones Islamic Market World Index revisions. Journal of Economic Behavior \& Organization, 132, 50-62.

Mossin, J. (1966). Equilibrium in a capital asset market. Econometrica, 34(4), 768-783.

MutebaMwamba, J., Hammoudeh, S., \& Gupta, R. (2017). Financial tail risks in conventional and Islamic stock markets: A comparative analysis. Pacific-Basin Finance Journal, 42, 60-82.

Narayan, P. K., Phan, D. H. B., Narayan, S., \& Bannigidadmath, D. (2017). Is there a financial news risk premium in Islamic stocks? Pacific-Basin Finance Journal, 42, 158-170.

Obaidullah, M (2005). Islamic Financial Services. Jeddah: Scientific Publishing Centre, King Abdulaziz University.

Shahzad, S., Ferrer, R., Ballester, L., \& Umar, Z. (2017). Risk transmission between Islamic and conventional stock markets: A return and volatility spillover analysis. International Review of Financial Analysis, 52, 9-26.

Shamsuddin, A. (2014). Are Dow Jones Islamic equity indices exposed to interest rate risk? Economic Modelling, 39, 273-281.

Sharpe, W. (1966). Mutual fund performance. The Journal of Business, 39(1), 119-138.

Tahir, M., \& Ibrahim, S. (2020). The performance of Shariah-compliant companies during and after the recession period-Evidence from companies listed on the FTSE All World Index. Journal of Islamic Accounting and Business Research, 11(3), 573-587.

Tanin, T. I., Ahmad, A. U. F., \& Muneeza, A. (2021). Shariah-compliant equities and Shariah screening: Need for convergence of ethical screening of stocks with Shariah screening. International Journal of Emerging Markets. https://doi.org/10.1108/IJOEM-09-2020-1041

Terraza, M., \& Mestre, R. (2020). Adjusted beta based on an empirical comparison of OLS-CAPM and the CAPM with EGARCH errors. International Journal of Finance and Economics. https://doi.org/10. 1002/ijfe. 1977 
Umar, Z., Shahzad, S. J. H., Ferrer, R., \& Jareño, F. (2018). Does Shariah compliance make interest rate sensitivity of Islamic equities lower? An industry level analysis under different market states. Applied Economics, 50(42), 4500-4521.

Publisher's Note Springer Nature remains neutral with regard to jurisdictional claims in published maps and institutional affiliations. 